\title{
Evaluation of Numerical Analysis forEarthquake Resistance of Retaining Wall Using Gabions
}

\author{
Tsuyoshi Nishia ${ }^{a *}$, Tadashi Hara ${ }^{\mathrm{b}}$, Hiroshi Nakazawa ${ }^{\mathrm{c}}$, Daisuke Suetsugu ${ }^{\mathrm{d}}$ \\ ${ }^{a}$ Construction Project Consultants, INC. Email: t_nishi@cpcinc.co.jp \\ ${ }^{\mathrm{b}}$ Centor for Disaster Prevention Promotion, University of Kochi. Email: haratd@kochi-u.ac.jp \\ ${ }^{c}$ Earthquake Disaster Mitigation Research Division, National Research Institute for Earth Science and Disaster Resilience. Email:nakazawa@ bosai.go.jp \\ ${ }^{\mathrm{d}}$ Department of Civil and Environmental Engineering Faculty of Engineering, University of Miyazaki. Email:suetsugu@cc.miyazaki-u.ac.jp
}

\begin{abstract}
In developing countries, gabions are widely used in several construction works, like road, river, countermeasures against slope failure and so on, because of their easy operation and low cost. In 2015 Nepal Gorkha Earthquake, a lot of retaining walls using gabions were not damaged against the strong earthquake because of their high flexibility. However, some deformation or declination were reported dpending on retaining wall types and ground conditions behind retaining walls. Therefore, in order to evaluate the earthquake resistance and residual deformations of retaining walls using gabions widely observed in Nepal, full-scale shake table tests and laboratory tests were conducted in previous studies. In this study, elemental simulations for determination of the analysis parameters based on the results of triaxial compression tests were carried out to check the validity of parameters. Then, a series of numerical analysis using proposed model was performed to reproduce the dynamic behaviors of full-scale shake table tests and evaluate the earthquake resistance of retaining wall using gabions. According to the results of these numerical analysis, it was confirmed that proposal model adequately could simulate the dynamic response of retaining walls in the full-scale shake table tests. and it was also cleared that the stepwise type retaining wall was superior to that of vertical type from the standpoint of earthquake stability against sliding and overturning.
\end{abstract}

Keywords: Earthquake resistance; gabion; numerical analysis; retaining wall; shaking table test

\section{Background}

The structures using gabions are widely used also in Japan as the structures on rivers, roads and coasts [1].

When the authors executed research of damage of civil/architectural structures caused by Nepal Gorkha Earthquake in 2015, it was confirmed that the retaining walls using gabions are widely used in Nepal [2]. Araniko Highway, objective of the research, is located about $10 \mathrm{~km}$ west of the place where the biggest aftershock occurred (Dolakha county), and at Barhabise along the Highway 42\% of houses were completely destroyed [3]. Almost all of the retaining walls using gabions were gravity type that gabions were straightly piled up, and some of them suffered from stick out or fall forward that are considered to be affected by external factor such as earthquake (Nepal Gorkha Earthquake) and rainfall. But in the area of the authors' research, the retaining wall itself using gabions did not reach

${ }^{*}$ Corresponding author. Tel.: +81-3-5337-4065

YSK Building 3-23-1 Takadanobaba Shinjuku-ku

Tokyo, Japan, 169-0075 the stage of collapse, but due to characteristics of soft structure of retaining walls using gabions, it was confirmed that minimum required performance to support life is held $[2,4-6]$. That is to say, minimum earthquake resistance that structure is deformed but not collapsed is proved in these retaining walls.

To evaluate the characteristics, and to grope more stable structures, the authors executed full-scale shake tests[7-11]. As the result of test, it was proved that upright retaining wall with height of $3 \mathrm{~m}$ widely used in Nepal does not collapse though big fall forward occurs by a large-scale earthquake [12]. This means that minimum performance proved in the above-mentioned examples of damages in Nepal was confirmed by the tests, but due to soft structure, measurement of deformation is considered to be in the range of not-negligible for the use conditions such as traffic of roads. Therefore, shape of leaning structure and stacking structure with improved stability was proposed, and judging from the deformed situation of structures, it was confirmed by tests that deformation related with stability such as fall down or sliding can be deterred. 
In this report, aiming to obtain basic data for the evaluation of the seismic stability of the retaining wall using gabions, reproductive analysis of the tests was conducted, comparison of superiority of structural shape on the seismic stability by the structural shape of the retaining wall using gabions and evaluation of structural problems were made.

\section{General Outline of Tests on the Earthquake Resistance of The Retaining Wall using Gabions}

Based on the utilization record of the retaining wall using gabions in Nepal, full-scale shake table tests were conducted to evaluate the earthquake resistance of them. This report is analytic evaluation of tests, and first of all, outline of fullscale tests and objective structural shape are stated.

Tests were conducted in 2016 and 2017 at National Research Institute for Earth Science and Disaster Resilience of Japan. Table 1 shows the outline of them. Basis of input earthquake motion of tests was sine wave of $3 \mathrm{~Hz}$ (peak shaking 12 waves) as the easily resonating frequency, and assumed maximum input acceleration was divided into 3 steps and was increased step by step. Further, test by whitenoise wave of $20 \mathrm{gal}$ of assumed maximum input acceleration was executed.

Figure 1 shows residual displacement of retaining wall using gabions as the result of tests. Legend in the Fig. shows maximum acceleration of input earthquake motion in the final stage. For the reference, maximum acceleration at the surface point of background was 400gal 600gal for the input acceleration. Input is sine wave, and as it has big energy compared with normal earthquake motion, actual earthquake motion works bigger than that shown in the figure with maximum acceleration.

In Fig. 1, residual displacement of the retaining wall is biggest in Case 1, and horizontal displacement in the levee

Table 1. Test Case (Objectives of analysis are Case $1 \&$ Case 2)

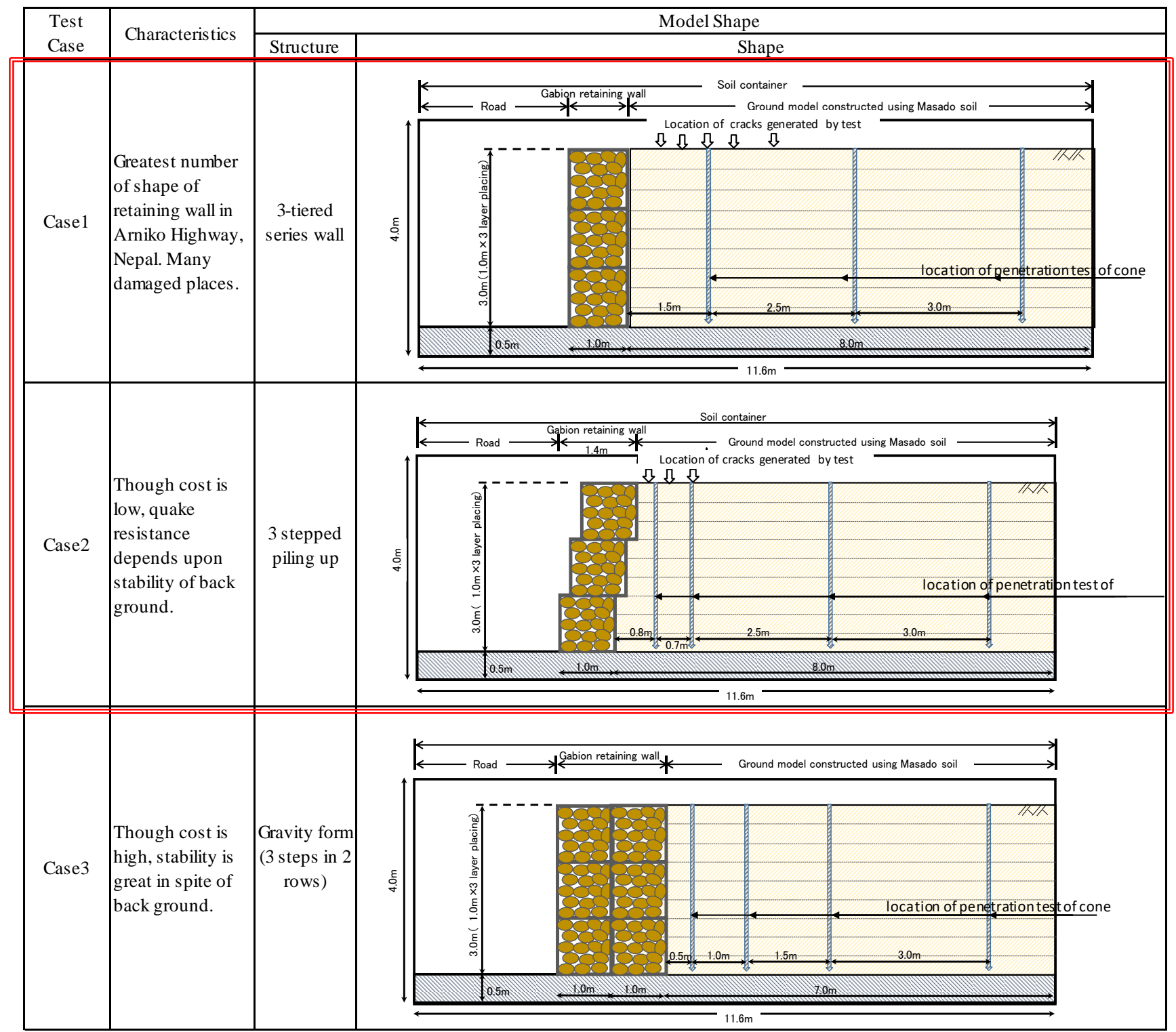


crown of $80 \mathrm{~cm}$ occurred, but such displacement I Case 2 and Case 3 is less than $20 \mathrm{~cm}$ which comparatively small. Angle to lean forward in Case 1 is more than 15 degrees, but from the fact that the wall does not fall down in spite of pressure of background, effect of soft structure was confirmed. After shaking test, dynamic corn penetration test was conducted. In case 1 and Case 3 straightly piled up, test was executed in the nearest place to the back side of retaining wall using gabions shown in Fig. 1, and the result shows that there is a tendency that penetration resistance decreases after test, but there was not a big change in Case 2.The reason for the difference is that Case 1 and Case 3 shows gravity resistance based on the self-standing structure of retaining wall using gabions, while in Case 2 of leaning structure, displacement of back ground is small.

Table 2 shows displacement of back ground in Case 1 and Case 2. The place where crack occurred is shown in Fig. 1, too. As a whole, there is a tendency that displacement of back ground in Case 1 is bigger, but especially in Case 2, first crack is occurred at very near the retaining wall using gabions, and cracks after it are occurred at the places nearer to the retaining walls than in Case 1. In this report, based on the abovementioned features, analytical evaluation is made about Case 1 with gravity resistance and Case 2 with lean forward structure surrounded by double red line in the table.

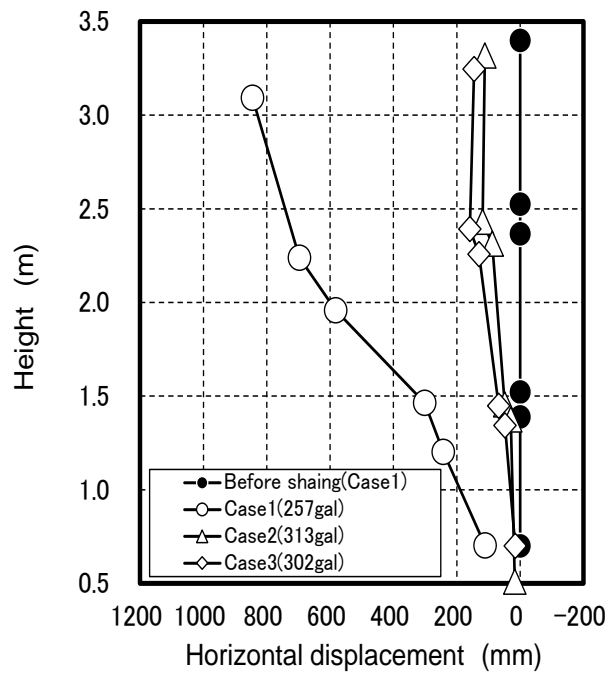

Figure 1. Residual displacement of Gabion [8]

Table 2. Situation of damages of back ground by test in Case 1 , case 2

\begin{tabular}{|c|c|c|c|}
\hline Case & $\begin{array}{c}\text { Structure of } \\
\text { gabions }\end{array}$ & $\begin{array}{c}\text { Input } \\
\text { Acceleration }\end{array}$ & Situation of the back ground \\
\hline \multirow{4}{*}{ Casel } & \multirow{4}{*}{$\begin{array}{l}3 \text {-tiered series } \\
\quad \text { wall }\end{array}$} & $65 \mathrm{gal}$ & No deformation \\
\hline & & $132 \mathrm{gal}$ & $\begin{array}{l}\text { Crack is generated at } 0.7 \mathrm{~m} \text { from back face } \\
\text { of wall and sliding collapse was caused }\end{array}$ \\
\hline & & 203gal & $\begin{array}{l}\text { cracks at } 1.1 \mathrm{~m}, \quad 1.6 \mathrm{~m}, 2.1 \mathrm{~m}, 2.8 \mathrm{~m} \\
\text { from wall }\end{array}$ \\
\hline & & $257 \mathrm{gal}$ & $\begin{array}{l}\text { By development of cracks in the range of } \\
1.1 \mathrm{~m} \text {, sliding collapse was caused }\end{array}$ \\
\hline \multirow{4}{*}{ Case2 } & \multirow{4}{*}{$\begin{array}{l}\text { 3-stepped } \\
\text { piling up }\end{array}$} & 85gal & No deformation \\
\hline & & $162 \mathrm{gal}$ & Cracks at $0.11 \mathrm{~m}$ from wall \\
\hline & & 244gal & $\begin{array}{l}\text { At } 0.55 \mathrm{~m} \text { from wall cracks were } \\
\text { generated and sliding collapse was caused }\end{array}$ \\
\hline & & 313gal & $\begin{array}{l}\text { By development of cracks in the range of } \\
1.1 \mathrm{~m} \text {, sliding collapse was caused }\end{array}$ \\
\hline
\end{tabular}

\section{Analysis Model}

\subsection{Analysis Model1}

Static analysis considering normal situation and dynamic analysis to evaluate seismic dynamic behavior were conducted. In static analysis, to get reference data for the future design of retaining walls, inertia force was worked statistically taking into consideration of measuring earthquake intensity. For analysis general-purpose FEM analysis program (Soil Plus) with two-dimensional finite element procedure (FEM) was used. Filling materials of gabions and back ground were modeled as plane twist factor, and gabions were modeled as the spring to prevent from deformation of filling materials. Joint factor was set, considering evaluation of sliding behavior between the gabions on the vertical line. And joint factor was set between gabions and back ground to consider sliding and detachment.

In static analysis, step analysis was made taking into consideration of construction stage. As Step 1, support base and earth tank were set, and in the order of 1st step of gabions, 1st layer of back ground, 2nd step of gabions, 7 steps were set up to 3rd layer of back ground. The stress inside the ground under the above conditions was set as the initial stress, and in the next step, horizontal inertia force was worked from back ground side to the side of retaining wall using gabions.

\subsection{Damage survey in Aranico Highway}

Filling materials, background and support ground were modeled as ground material with plane twist factor. Set value of physical property of each material is shown in Table 3. Unit volume weight of filling material was set with weight of rocks filled in the gabions. Back ground and support ground are set as solid ground compacted enough. Set rigidity modulus, strength parameters and so on are shown below. Characteristics of joint factor was set as very big value $\left(\mathrm{K}=10^{7} \mathrm{kN} / \mathrm{m}^{2}\right)$ so that joint rigidity in orthogonal direction against joint face would not encroach. Shear direction was set as $\mathrm{Ks}=10^{4} \mathrm{kN} / \mathrm{m}^{2}$ which is a little bit bigger than spring value of band of gabions, and friction coefficient was set as $\mu=0.6$ which is a little bit smaller than $\mu=0.67$ comparable with inner friction angle of filling materials.

\subsubsection{Value of physical property used in static analysis}

In static analysis, strength-deformation characteristics of filling materials was set based on hyperbolic model by Duncan-Chang [13]. Fitting of hyperbolic model was based on the result of triaxial compression test of materials with particle size similar to filling materials used for test[14]. Figure 3 shows the result of triaxial compression test in laboratory and outcome of fitting. Here, actual height of retaining wall using gabions used for shaking table test was $3 \mathrm{~m}$, and as action stress was supposed to be maximum $50 \mathrm{kN} / \mathrm{m}^{2}$, in fitting, conformity of $\sigma_{\mathrm{c}}=32 \mathrm{kN} / \mathrm{m}^{2}$ with small 


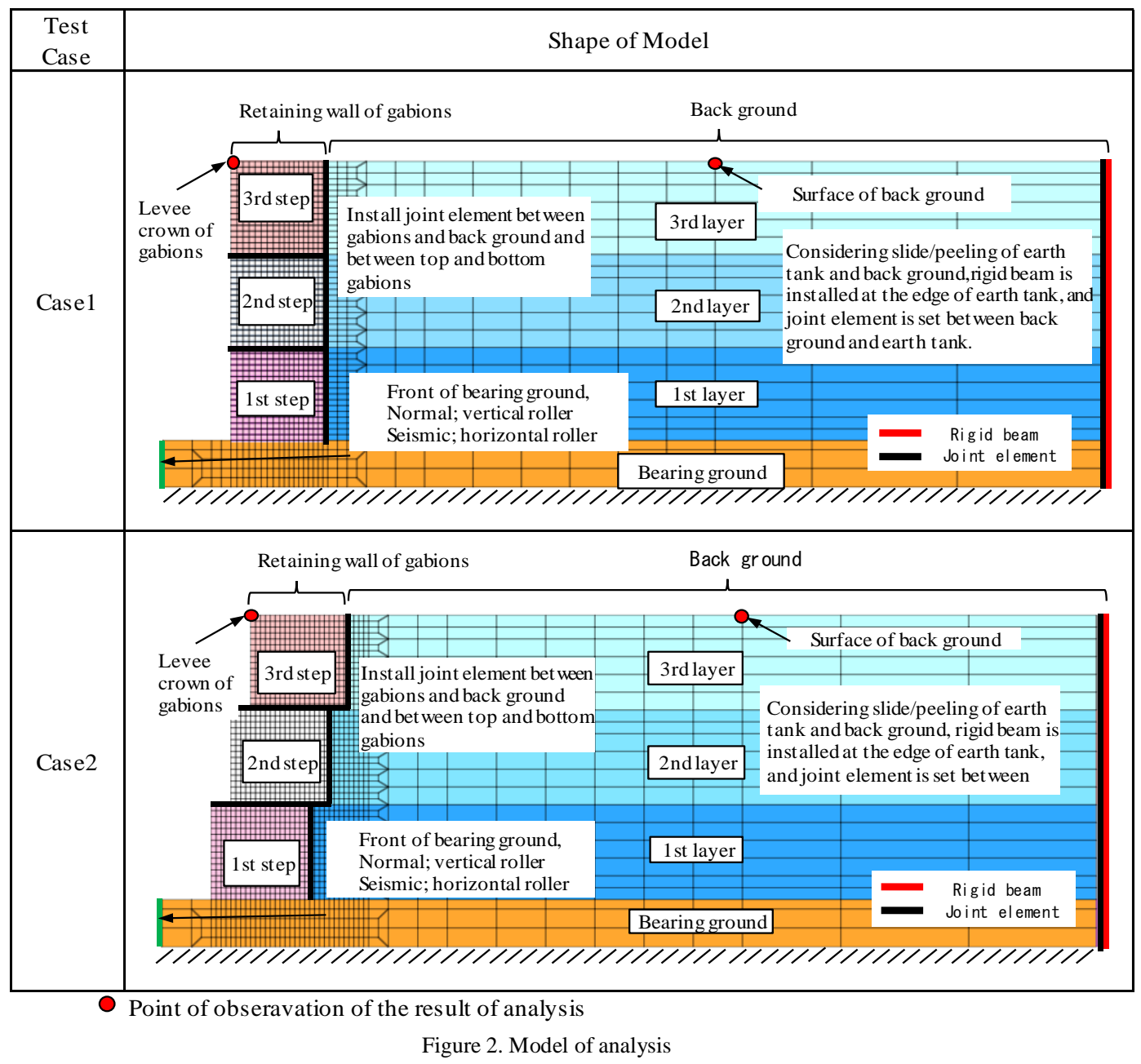

confined pressure and $64 \mathrm{kN} / \mathrm{m}^{2}$ was fully considered. Figure 4 shows result of triaxial compressive test (CD test) of background and materials of support ground. From Fig. 4, it was judged to be more appropriate to apply elasto-plasticity conditions of by-linear type than applying hyperbolic model to the relations of stress-twist of these materials, and nonlinear characteristics was evaluated with by-linear model by Mohr-Coulomb. Figure 4 shows result of test and setting value on analysis. Deformation coefficients are set, like the filling materials, to conform to the area with confined pressure. In test, phase difference was confirmed between retaining wall using gabions and back ground. Therefore, judging that tensile stress works on the back ground with the horizontal power under the conditions that back ground is not restrained after gabions move by themselves, model with non-tension type was adopted.

In this study, as having been mentioned in the above, influence of fictious force was considered in static analysis. In tests, as deformation of back ground by shaking occurs especially in the back of retaining wall using gabions, twist is considered to reach the size of several \% exceeding rupture zone. Therefore, as peak strength in Table 3 can not be exerted, in analysis to exert inertia force, strength of back ground was applied with residual strength shown in ( ) of Table 3 .

\subsubsection{Value of physical property used in dynamic analysis ( $R$-O model parameter)}

Dynamic characteristics of filling materials and back ground are shown in Table 4. Here, non-linear nature was considered by Ramberg-Osgood (R-O) model. For back ground dynamic deformation characteristic test by indoor triaxial compressive test is conducted, and standard twist $\gamma_{\mathrm{r}}$ and maximum decay rate $h_{\max }$ were set to make fitting with the test. Figure 5 shows the result of fitting. Here, standard twist is set so that it would fit to the twist with size of $\gamma=1.0 \times 10^{-3}$. In small twist area less than $\gamma=10^{-4}$ and large twist area more than $\gamma=10^{-2}$ there is a small gap, the reasons for having considered middle twist area of around $\gamma=10^{-3}$ are as follows; judging from size of shaking, test was supposed to be in the twist area bigger than $10^{-4}$, twist is not supposed to be in the range evaluated by R-O model, because in the large twist area, ground rupture will be accompanied as a real phenomenon.

On the other hand, regarding filling materials, as there is not any result of dynamic deformation test, value was estimated from the existing documents. Tanaka.et.al.[15] conducted dynamic deformation characteristic test and the result shows that reduction of rigidity occurs in comparatively small twist area (standard twist $\gamma_{\mathrm{r}} \leqq 4 \times 10^{-4}$ ). 
Table 3. Static value of physical property of ground material

\begin{tabular}{|c|c|c|c|c|c|c|}
\hline \multirow[b]{2}{*}{ Name } & \multirow[b]{2}{*}{$\begin{array}{c}\text { Poisson ratio } \\
v\end{array}$} & \multirow{2}{*}{$\begin{array}{c}\text { Young's } \\
\text { modulus } \\
E\left(k N / \mathbf{m}^{2}\right)\end{array}$} & \multirow{2}{*}{$\begin{array}{c}\text { Unit Volume } \\
\text { weight } \\
\gamma\left(\mathbf{k N} / \mathbf{m}^{3}\right)\end{array}$} & \multicolumn{2}{|c|}{ Strength parameter ${ }^{※)}$} & \multirow[b]{2}{*}{ Remarks } \\
\hline & & & & $\begin{array}{c}\text { Cohesive Force } \\
\mathbf{c}\left(\mathbf{k N} / \mathbf{m}^{2}\right)\end{array}$ & $\begin{array}{c}\text { Angle of } \\
\text { internal friction } \\
\varphi(\text { deg })\end{array}$ & \\
\hline Filling material & 0.330 & 29,037 & 16.0 & 15.0 & \begin{tabular}{|l|}
34.0 \\
\end{tabular} & DC model \\
\hline Back ground & 0.330 & 15,000 & 20.0 & $20.5(4.0)$ & $38.0(38.5)$ & Mohr-Coulomb \\
\hline Foundation & 0.330 & 20,000 & 20.0 & - & - & Elasticity \\
\hline
\end{tabular}

Table 4. Dynamic value of physical property of ground material

\begin{tabular}{|c|c|c|c|c|c|c|c|}
\hline \multirow{2}{*}{ Name } & \multirow{2}{*}{$\begin{array}{l}\text { Poisson`s } \\
\text { ratio } \\
v\end{array}$} & \multirow{2}{*}{$\begin{array}{c}\text { Velocity of } \\
\text { elastic wave } \\
\text { Vs }(\mathbf{m} / \mathbf{s})\end{array}$} & \multirow{2}{*}{$\begin{array}{c}\text { Initial rate of } \\
\text { shear rigidity } \\
\mathbf{G}_{0}\left(\mathbf{k N} / \mathbf{m}^{2}\right)\end{array}$} & \multirow{2}{*}{$\begin{array}{l}\text { Unit weight } \\
\gamma\left(\mathbf{k N} / \mathbf{m}^{3}\right)\end{array}$} & \multicolumn{2}{|c|}{ Non linear characteridtic } & \multirow{2}{*}{$\begin{array}{c}\text { Standard confined } \\
\text { pressure }^{\star)}\end{array}$} \\
\hline & & & & & $\begin{array}{c}\text { Standard strain } \\
\gamma_{\mathrm{r}}\end{array}$ & $\begin{array}{l}\text { Maximum damping } \\
\text { factor } \mathbf{h}_{\max }\end{array}$ & \\
\hline filling material & 0.450 & 200.0 & 65,262 & 16.0 & $5.00 \mathrm{E}-05$ & 0.20 & $\sigma_{\mathrm{c}}=24 \mathrm{kN} / \mathrm{m}^{2}$ \\
\hline Back ground & 0.450 & 200.0 & 81,577 & 20.0 & $1.60 \mathrm{E}-04$ & 0.20 & $\sigma_{\mathrm{c}}=50 \mathrm{kN} / \mathrm{m}^{2}$ \\
\hline Foundation & 0.450 & 200.0 & $\mathbf{8 1 , 5 7 7}$ & 20.0 & 1.60E-04 & 0.20 & $\sigma_{\mathrm{c}}=50 \mathrm{kN} / \mathrm{m}^{2}$ \\
\hline
\end{tabular}

※)Rate of shear regidity and standard twist are supposed to be proportionate to 0.5 th power of standard confined pressure

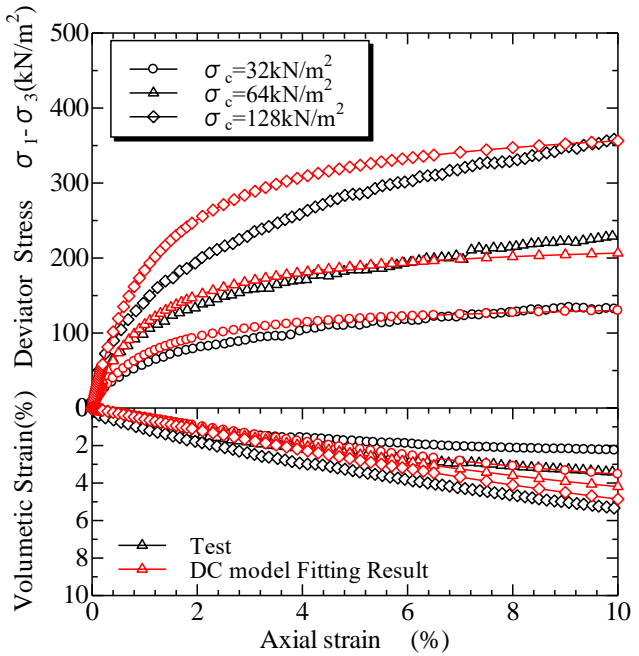

Figure 3. Deviator Stress-Axial Strain-Volumetic Strain Relation of Filling materials

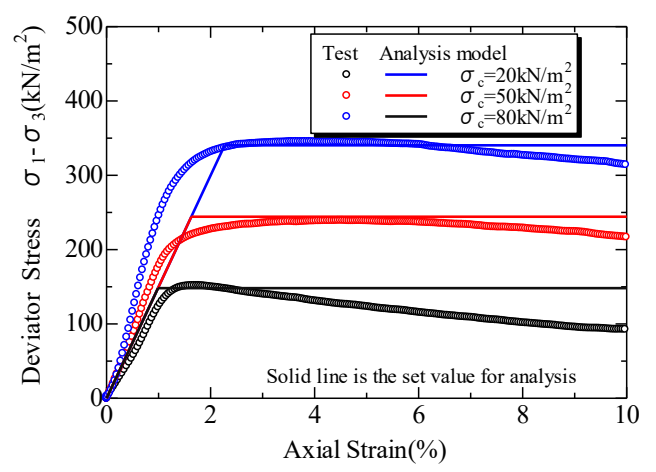

Figure 4. Deviator Stress-Axial Strain Relation of Back ground and Foundation

As filling materials are composed of rocks without fine grain, and confined pressure on the three-tiered gabions is small, ratio of reduction of rigidity against twist is supposed to be bigger than the result of test by Tanaka et.al. So, standard twist under confined pressure at the height of center of gabions $(1.5 \mathrm{~m})$ was set as $\gamma_{\mathrm{r}}=5.0 \times 10^{-5}$. As for maximum decay rate $h_{\max }, h_{\max }=0.20$ as general value was set.

Among the dynamic values of physical property, initial shear modulus of rigidity $\mathrm{G}_{0}$ and standard twist in Table 4 are given as the value under standard confined pressure in the Table, and these are set to change in proportion to power of 0.5 of confined pressure.

\subsubsection{Value of physical property used in dynamic analysis} (initial ratio of shear modulus of rigidity)

Initial shear modulus of rigidity $\mathrm{G}_{0}$ was obtained from this full scale test and full scale test of simple body of retaining wall using gabions. Based on the response characteristics at the moment of input of white noise wave, trial analysis with parameter of speed of shear bouncing wave Vs was executed.

Figure 6 shows Fourier spectrum ratio (transfer function) between response acceleration at levee crown and input acceleration by white noise wave against simple body model of retaining wall using gabions shown in Fig. 9. The results of analysis with the conditions of Vs $=180 \mathrm{~m} / \mathrm{s}, 190 \mathrm{~m} / \mathrm{s}$, $200 \mathrm{~m} / \mathrm{s}$ under standard confined pressure of gabions are shown with result of tests. In the cases of $V s=180 \mathrm{~m} / \mathrm{s}$, $190 \mathrm{~m} / \mathrm{s}$, primary peak of frequency is a little bit lower compared with result of test, and the case of $\mathrm{Vs}=200$ expresses most nearly result of tests. In Fig. 6, except primary peak, result of analysis exceeds that of tests. Therefore, in analysis it is possible to give rather big response acceleration. There is possibility that frictional force between rocks of filling materials influence to response, and decay effect bigger than supposition was born, but tendency as a whole does not change so big. The purpose of Fig. 6 is setting of initial stiffness of filling materials of retaining wall using gabions, from this viewpoint, as primary 


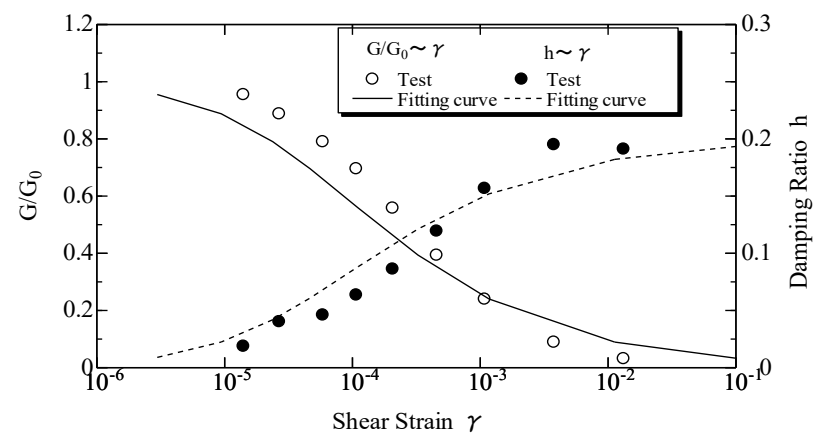

Figure 5. Dynamic deformation characteristics of Back ground and Foundation

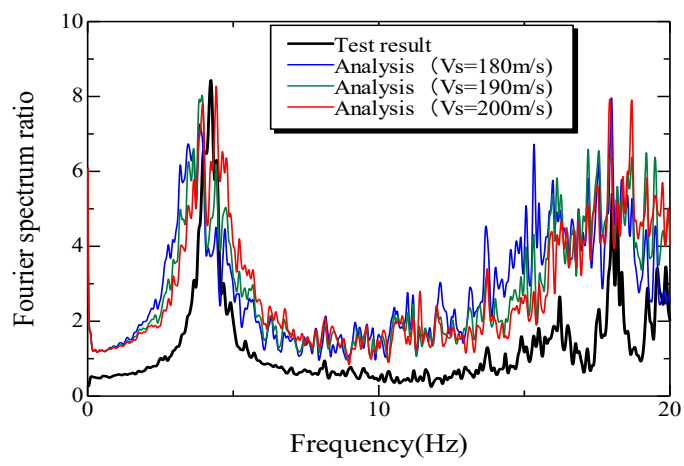

Figure 6. Transfer function of the gabions
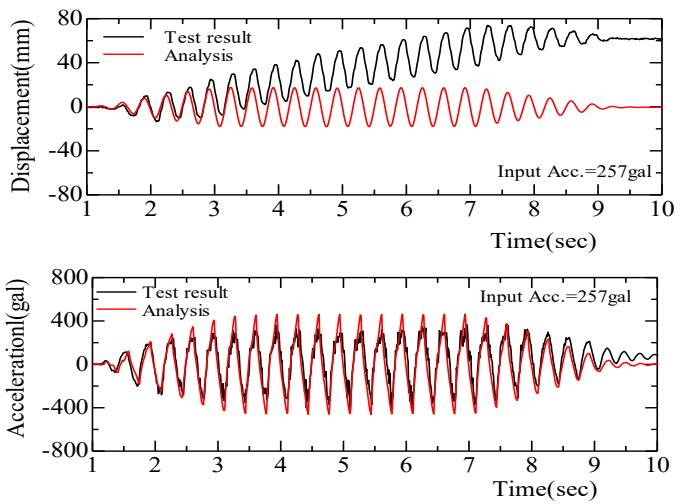

Figure 7. Comparison of the top response of gabions

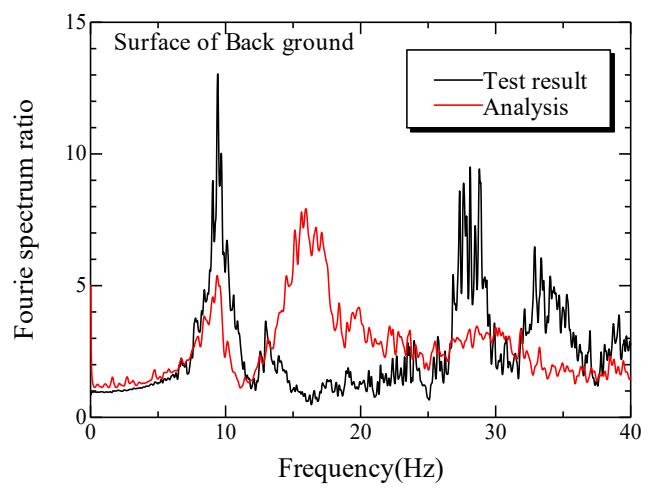

Figure 8. Transfer function of Test case1
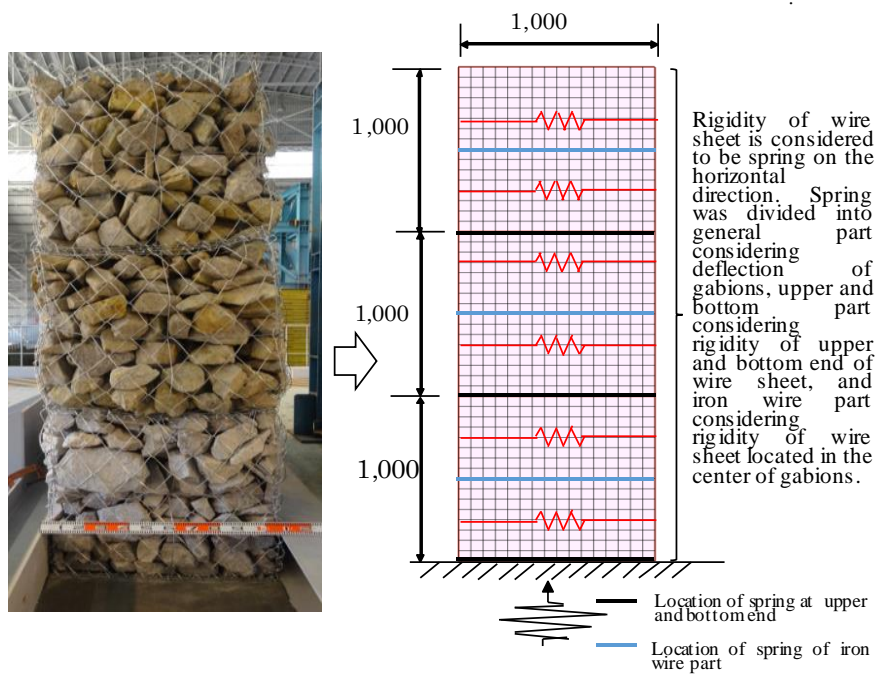

Figure 9. Modelization of band of gabions

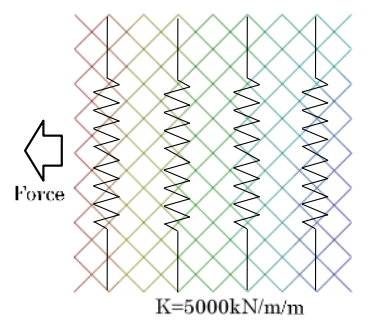

Figure 10. Calculation model for bando of gabions

Table 5. Spring coefficient band of gabions

\begin{tabular}{c|r|c}
\hline location & \multicolumn{1}{|c|}{ Value } & Unit \\
\hline general part & 269.8 & $\mathrm{kN} / \mathrm{m} / \mathrm{m}$ \\
\hline upper and bottom end & 4071.7 & $\mathrm{kN} / \mathrm{m}$ \\
\hline iron wire & 426.4 & $\mathrm{kN} / \mathrm{m}$ \\
\hline
\end{tabular}

peak of result of test coincide with that of result of analysis, it is concluded that there is applicability as a result.

Figure 7 shows response acceleration and response displacement at the levee crown of retaining wall using gabions at the time of inputting sine wave of $257 \mathrm{gal}$ in the same model. In Fig. 6, though analysis showed possibility to give a little bit big acceleration, rather big acceleration is given. Regarding response displacement, displacement amplitude itself does not change so much between the result of analysis and that of test, result of test is accumulated in one direction. This is effect of asymmetric nature of retaining wall using gabions, it is supposed that direction of accumulation will differ by conditions of placement of filling materials with random form. The purpose of this analysis is evaluation of stability by structure shape. From this viewpoint, comparatively good result including Fig. 6 was obtained.

Figure 8 shows, using model of Case 1 in Fig. 2, spectral ratio of input acceleration at the levee crown of retaining wall using gabions and at surface of back ground ( ref. Fig. 2) when $V s=200$ is set under confined pressure of 
background. In each point, primary proper period reproduces result of test. Displacement of secondary and onwards peak is seen, but effect of boundary conditions by earth tank which are not expressed in two-dimensional analysis is supposed. As shaking wave is basically $3 \mathrm{~Hz}$, effect of wave of more than $10 \mathrm{~Hz}$ to the result is supposed to be small. Like in Fig. 6, from the viewpoint that this figure aims setting of initial stiffness of back ground, applicability of result is proved.

As above, $\mathrm{Vs}=200 \mathrm{~m} / \mathrm{s}$ is appropriate as Vs under standard confined pressure of back ground. For the reference, initial stiffness ratio Go by dynamic deformation test of back ground is about $67000 \mathrm{kN} / \mathrm{m} 2$, if it is converted to Vs, it become about $180 \mathrm{~m} / \mathrm{s}$. It is a little bit smaller than supposition, but as difference is about $10 \%$, it shows comparatively good coincidence. If you compare Fig. 6 and Fig. 8, proper period of the levee crown of retaining wall using gabions are around $4 \mathrm{~Hz}$ and $9 \mathrm{~Hz}$, differs by Figures. It is supposed that in a model with back ground, response of back ground with bigger mass will govern.

\subsection{Modeling of band of gabions (wire sheet)}

Retaining wall using gabions is a structure composed of filling materials and wire sheet holding them (here it is called band of gabions). In modeling of band of gabions, it is necessary to consider stereoscopic behavior, but in this study two-dimensional model is used, and if beam model is applied to band of gabions, constraint effect of filling materials cannot be expressed. So, as Figure 10 shows, modeling was made by supposing band of gabions as horizontal spring.

Value of spring was obtained as follows. Tensile resistance of rhombus wire sheet used for band of gabions is affected by compressive stiffness of filling materials. That is to say, if deformation of filling materials does not occur, deformation of band of gabions by pull force depends only on tensile stiffness of wire sheet, but actually, by compressive deformation of filling materials, band of gabions become deformable. Considering this fact, as Fig. 10 shows, under the conditions that compressive stiffness of filling materials is considered as confined spring of band of gabions in the vertical direction, from the displacement obtained by giving horizontal power to band of gabions, value of spring was calculated from relationship with active horizontal power. Compressive stiffness of filling materials is set based on Young's modulus $\left(\mathrm{E}=5,000 \mathrm{kN} / \mathrm{m}^{2}\right)$ under the condition of low confined pressure $\left(\sigma c=32 \mathrm{kN} / \mathrm{m}^{2}\right)$ based on Fig. 3. Spring values of band of gabions obtained in the said way are shown in Table 5. Spring is divided into general part that deflection of gabions is considered as above, part of top and bottom end considering stiffness of wire sheet set in the top and bottom end of gabions, and part of iron wire considering stiffness of wire sheet put on the center of gabions. In the table, as general part is supposed from displacement of whole gabions, and the others are supposed from stiffness of wire sheet as iron wire, unit of both differs.

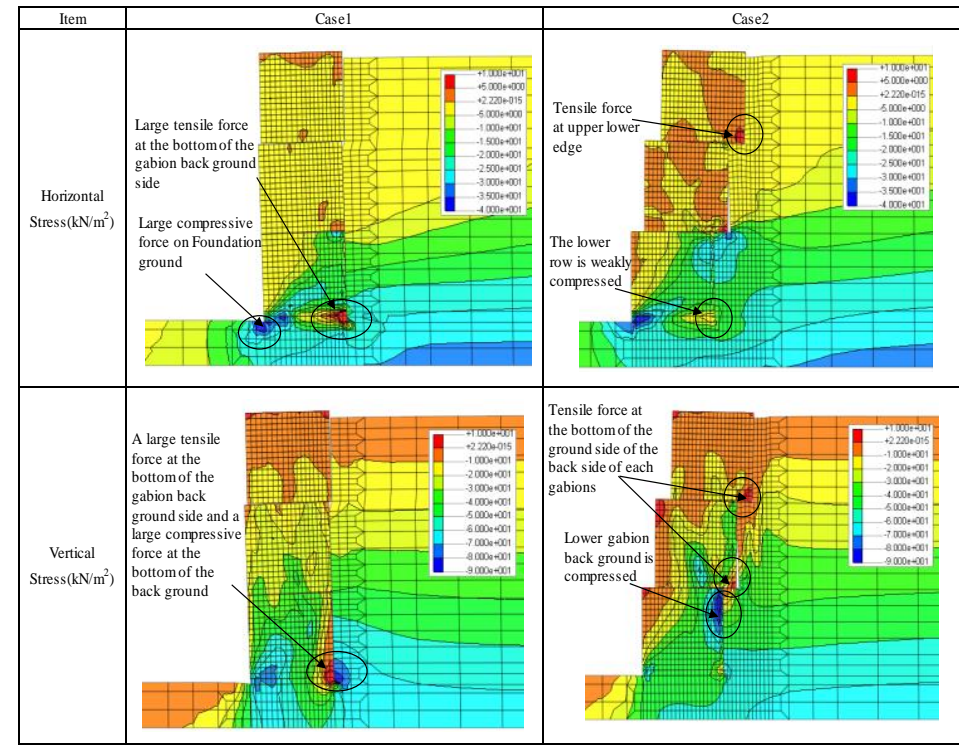

Figure 11. Horizontal and vertical stresses by static analysis (Deformation magnification 10x)

\section{Result of Analysis and Consideration}

\subsection{Static analysis}

As the result of static analysis considering situation before shaking,distribution of horizontal stress and vertical stress in the ground is shown in Fig. 11. Minus of stress in the figure shows compressed state. Here, deformation mode is shown with condition that magnification ratio of deformation was decupled of actual one.

In case where horizontal stress is compared, in Case 1, pull force of more than $10 \mathrm{kN} / \mathrm{m} 2$ works on retaining wall using gabions in the bottom end on the side of back ground. On the front side, tensile stress of more than $40 \mathrm{kN} / \mathrm{m} 2$ works on the support ground. This is considered to be caused by sliding power of retaining wall using gabions. On the other hand, in Case 2, pull force occurs on the gabions put on upper stage, but in the lower stage, there is not pull force area, but whole lower stage become compression area.

In case where distribution of vertical stress is compared, in Case 1, tensile stress of more than $10 \mathrm{kN} / \mathrm{m}^{2}$ occurs in the lower part of retaining wall using gabions on the side of back ground, and compression stress of more than $90 \mathrm{kN} / \mathrm{m} 2$ occurs on the adjacent back ground. This phenomenon is considered to occur by fall down mode of retaining wall. On the other hand, in Case 2, pull force area occurs on the upper stage and bottom end of middle stage of gabions, but lowest stage is in compression state, structure that is difficult to fall down is brought. If you consider relationship between stress of back ground and twist shown in Fig. 4, stability is not diminished by stress inside ground, but stability against sliding by external power of earthquake and rain fall etc. and fall down is relatively low in Case 1 .

Figure 12 shows minimum main stress at time of working horizontal inertia force. Like Fig. 11, deformation mode is shown with condition that magnification ratio of 
deformation was decupled of actual one. In the figure, location where crack occurs and area of sliding disruption after final shaking which were obtained from damage state of back ground at time of stage shake shown in Table 2 . While in Case 1 first crack occurs at the location of $70 \mathrm{~cm}$ from retaining wall, in Case 2 location of crack was the very near point of $11 \mathrm{~cm}$ from the retaining wall using gabions. In Case 2, big tensile stress is generated at the point very near the retaining wall using gabions, it is supposed that crack is generated very near the back side of retaining wall using gabions. In case 1, such local tensile stress as being observed in Case 2 is not found, but work of tensile stress is observed in rather wide area near the surface layer. Range of tensile stress near the surface layer, both in Case 1 and Case 2, is inclined to spread, and coincide with the process to generate crack at the distant place from the retaining wall using gabions with increase of shaking acceleration observed in test. Figure 13 presents maximum shear stress at time of action of horizontal inertia force. Like Fig. 12, location of generating crack and range of sliding disruption are shown. Like minimum principal stress, shear stress increases near location of generating crack, the range with big shear stress spreads on the back side with the increase of earthquake intensity. Both minimum principal stress and maximum shear stress are bigger in Case 2 at the location of back side of gabions shown in the figure. This is supposed to be caused by following factors. That is to say, as unit volume weight of back ground is bigger than that of filling materials of gabions, acting load on back ground is bigger than that just beneath the gabions. For this reason, vertical stress just beneath the gabions differs from that of back ground near the gabions, and gap is generated on the ground under the gabions. Then, gabions fall down on the back ground. As the result, shear force by friction is generated between back ground and the retaining wall using gabions, and local sliding disruption occurs. Further, if inertia force is worked, retaining wall using gabions leans forward and at the same time, because of step shape, gabions on the step give upward shear force to back ground, and with this big shear force and tensile force work to back ground near the gabions. For this reason, crack is generated very near the gabions. If inertia force increases, lean forward of retaining wall using gabions increases, gap will be born between back ground. For this reason, active disruption is generated on the back ground, and with the increased lean of the retaining wall using gabions, as gap progresses towards deep part, range of active disruption is widened. On the other hand, in Case 1, size of fall increases due to problem of stability of retaining wall itself using gabions, back ground will be destabilized. In Fig. 12 and Fig. 13, leaning line of retaining wall using gabions under conditions of intensity 0.2 was shown. Lean in Case 1 is a little bit bigger, and stability against falling is higher in Case 2.

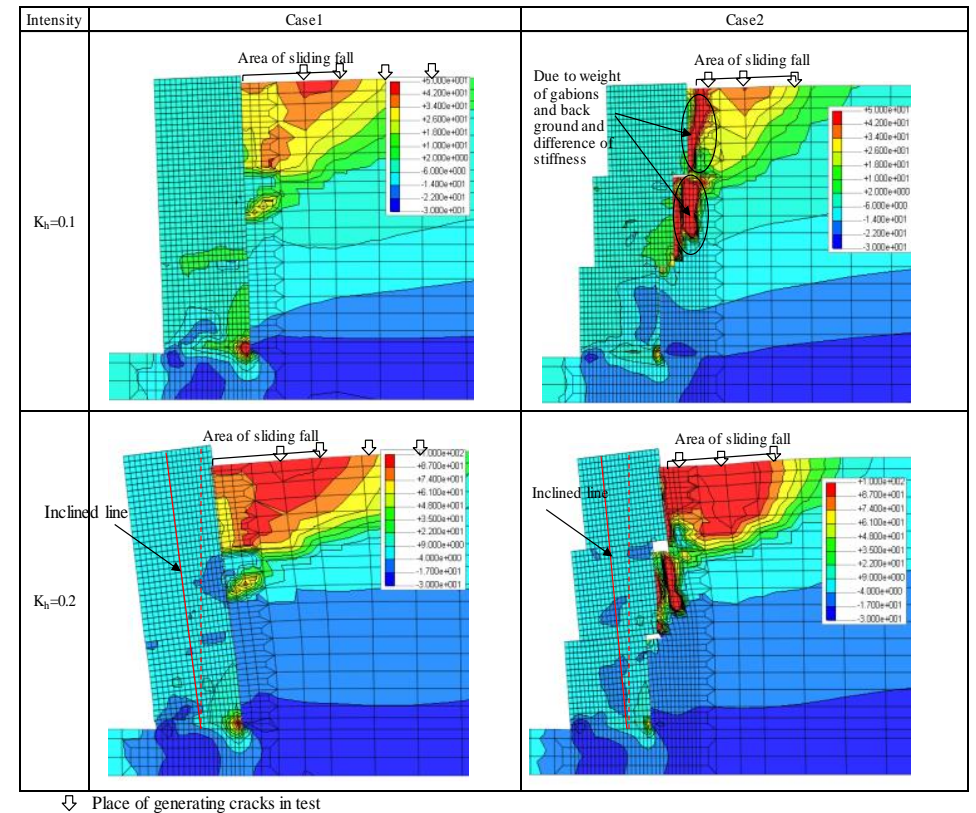

Figure 12. Minimum principal stress under horizontal inertial force (Deformation magnification 10x)

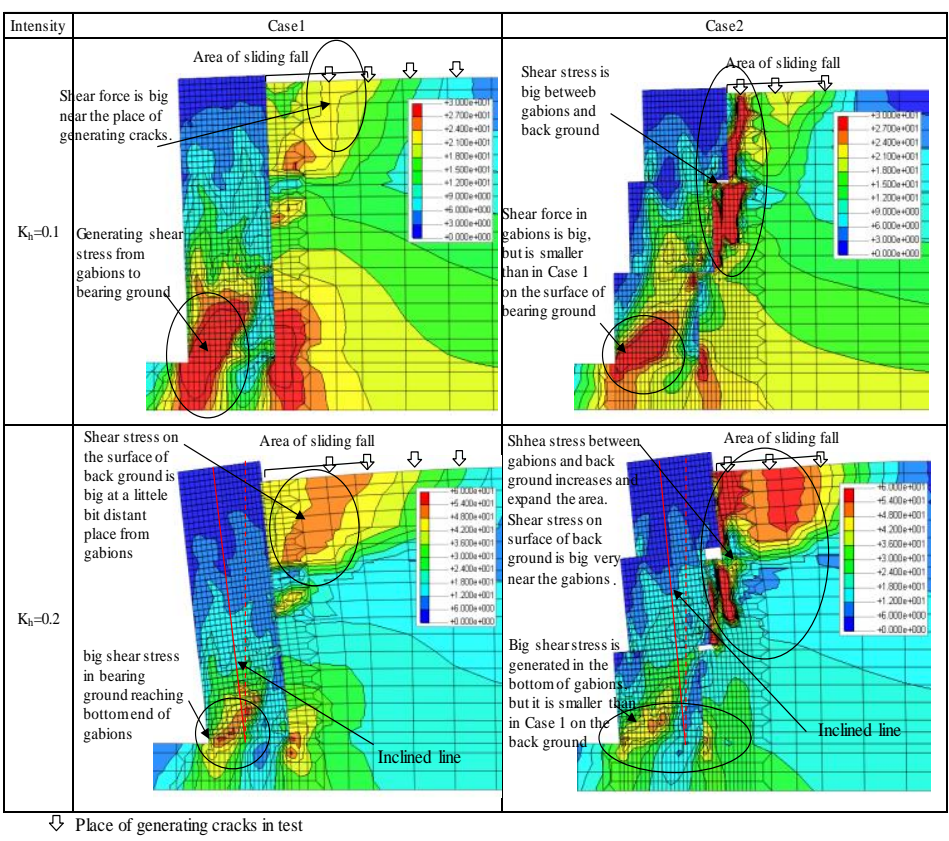

Figure 13. Maximum shear stress under horizontal inertial force (Deformation magnification 10x)

\subsection{Dynamic analysis}

Figures 14 17 show time history of acceleration and displacement by dynamic analysis at the levee crown of the retaining wall using gabions and on the surface of back ground (ref. Fig. 2). In every case, objective is 1st, 2nd step of shaking step of sine wave. In the result of Case 1 shown in Fig. 14, under conditions of input acceleration 65gal, acceleration at the at the levee crown of the retaining wall using gabions and on the surface of back ground in the result of test and that in the result of analysis almost coincide. Regarding displacement, result of analysis shows a little bit 
bigger value on the surface of back ground, but result of test and analysis almost coincide at the levee crown of the retaining wall using gabions. On the other hand, under the conditions of shaking 132gal shown in Fig. 15, acceleration at the levee crown of the retaining wall using gabions in the result of analysis is a little bigger at minus side than that in the result of test, and displacement in the result of test shows tendency to be accumulated by shaking, but accumulation of displacement by shaking is small in the result of analysis. In Case 2 shown in Fig. 16, result of test and result of analysis of acceleration at the stage of $85 \mathrm{gal}$ almost coincide, but displacement at the levee crown, like the case of shaking 132gal in Case 1, does not express accumulated displacement in the result of test. Further, in the case of 162gal shaking shown in Fig. 17, acceleration at the levee crown of the retaining wall using gabions in the result of analysis is smaller than that in the result of test, and the displacement at the same place in the result of analysis is smaller too than that in the result of test. From the above, it can be concluded that at the stage of low shaking level, result of test and result of analysis in Case 1 coincide well, but that at the higher shaking level, result of analysis cannot express result of test. In Case 2, in the degree of shaking $85 \mathrm{gal}$, result of analysis cannot express displacement of the retaining wall using gabions in the result of test.

It is indicated that in the test, at the stage of low shaking level, the retaining wall using gabions behaved as a unit, but at the higher shaking level phase difference of response occurs. It is possible that by the said behavior, relative displacement occurs between the retaining wall using gabions and back ground. From this, Figure 18 shows time history of relative value, by analysis, of displacement between the levee crown of the retaining wall using gabions (back ground side) at the time of shaking 132gal in Case 1 and the back ground at the same location. Relative displacement (difference of displacement) has tendency to be increased, but there is a moment of displacement 0 when both crashes.

Figure 18 shows the time when space between the both become big $(\mathrm{t}=4.18$ second and 4.16 second, input acceleration 132gal), and Fig. 19 shows deformation mode (magnification ratio of deformation 20 times) at the time of crash ( $\mathrm{t}=4.36$ second and 4.30 second, input acceleration 162gal). Upper line of the light green zone in Fig. 19 indicates horizontal stress. In Case 1, at the moment of opening, tensile stress (plus side) in the horizontal direction occurs, and at the moment of crash, stress at the side of compression (minus side) occurs on the whole.

If you consider real behavior in the test, back ground is disrupted by the above mentioned repetition of compressiontensile, sliding disruption occurs by generation of cracks and progress of them. Earth and sand on the sliding surface sinks between the retaining wall using gabions and back ground at the moment when space opens and fulfill the space. For this reason, retaining wall using gabions cannot return to the original location at the time of next closing behavior, and as
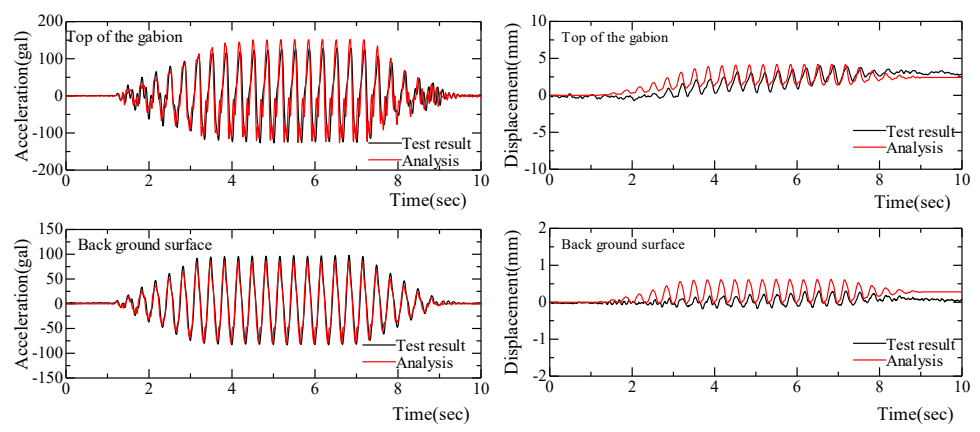

Figure 14. Response value in test case 1 (Input Acc.=65gal)
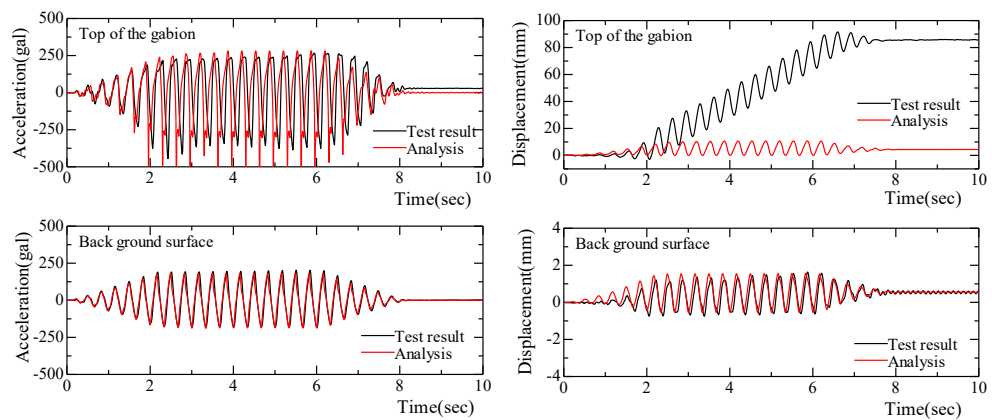

Figure 15. Response value in test case 1 (Input Acc.=132gal)
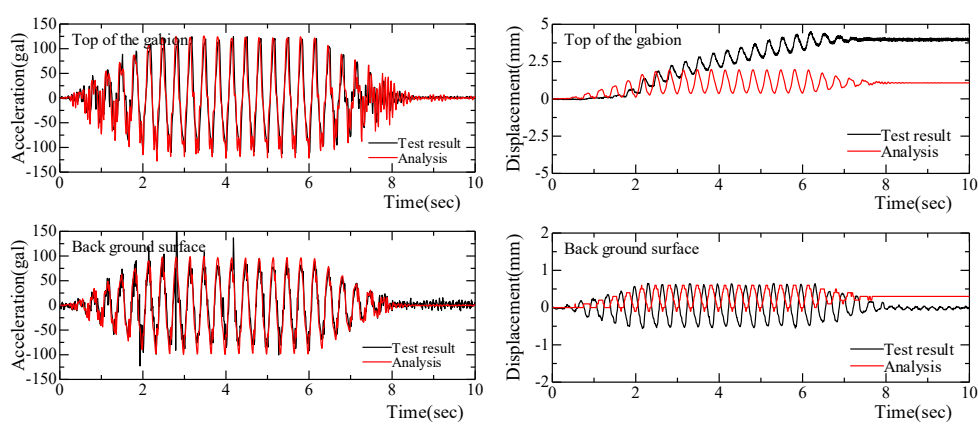

Figure 16. Response value in test case 2 (Input Acc.=85gal)
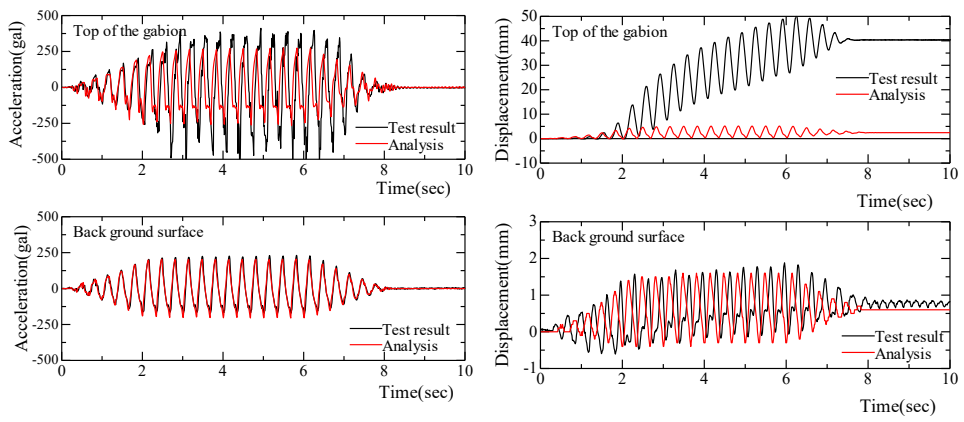

Figure 17. Response value in test case $2($ Input Acc.=162gal)

a result, displacement cumulatively increases. At the stage of low shaking level, this influence is small and big difference does not occur between the result of test and that of analysis, but with increase of shaking level, difference of displacement behavior increases, and result of test cannot be adequately expressed by analysis. Further, as adequate evaluation of crash behavior between the retaining wall 


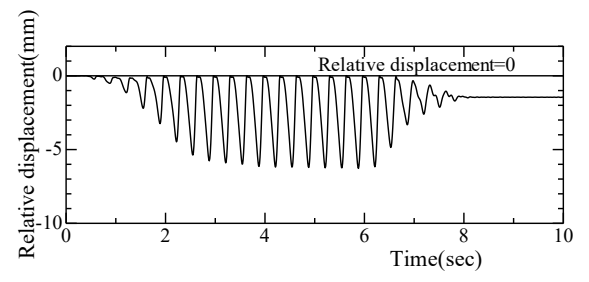

Figure 18. Relative displacement of gabion retaining wall and back ground in test case1(Input Acc.=132gal)

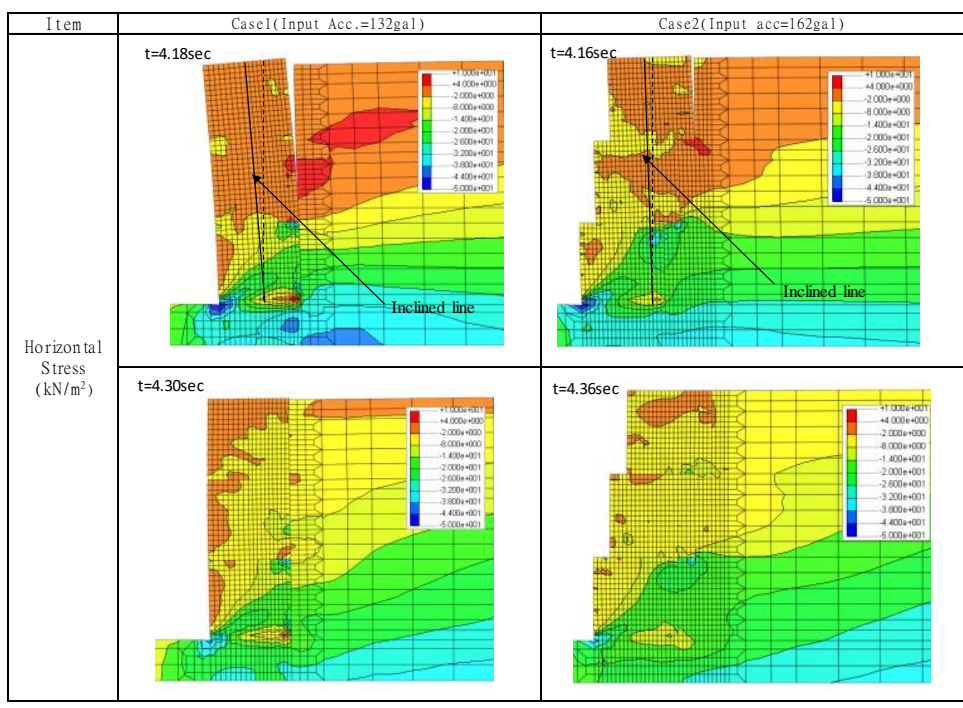

Figure 19. Deformation mode and horizontal stress distribution by dynamic Analysis (Deformation magnification 10x)

using gabions and back ground is difficult, with the increase of shaking level, difference of acceleration increases.

Regarding discordance of result of analysis in Case 2, as Fig. 12 and Fig. 13 shows, local tensile stress and shear stress work between the retaining wall using gabions and back ground, and though it cannot be confirmed visually, itis possible that local breaking surface is generated very near the retaining wall using gabions even at comparatively low shaking level. Therefore, like the case of high shaking level in Case 1, it is supposed that displacement at the levee crown of gabions takes behavior to increase cumulatively. However, though in Case 2 local breaking behavior is watched, as having been indicated, from the viewpoint of stable behavior as a whole, stability is better than Case 1. In Fig. 19, like Fig. 12 and Fig. 13, inclination line is shown about the result of time when space expands, and angle of inclination in Case 1 become comparatively bigger than in Case 2. For this reason, as Fig. 1 shows the result of test, residual displacement after shaking in Case 2 is considerably smaller than that in Case 1.

As above, in this analysis, there is a part that behavior in test is not adequately evaluated. However, it is very difficult to express in analysis behavior of cumulative displacement generated by falling of local breaking surface, and it is considered to be limit of analysis. Purpose of this analysis is comparison of superiority of structural shape with a view to establish a future design method and evaluation of structural problems and so on. From this viewpoint, like evaluation of local point of stress concentration by static analysis, evaluation of behavior of each structure was made in the analysis conducted this time.

\section{Conclusion}

With the retaining wall using gabions widely used in Nepal, full-scale shake table test was conducted. From the outcome of this test, about test Case 1 with gravity resistance and test Case 2 of lean type, evaluation by static analysis with finite element method (FEM) and dynamic analysis were conducted. Findings obtained in the study are as follows:

(1) As the result of static analysis, from the viewpoint of stability, it is possible that in Case 1 problems of sliding and falling occur easily and stability of lean type in Case 2 is higher.

(2) In case 2, partially big tensile stress and shear stress works on the back ground near the retaining wall using gabions. This is because of difference of weight of retaining wall using gabions and back ground and difference of behavior of retaining wall using gabions and back ground at the moment when inertia force works, and with these influence, in Case 2 cracks are easily generated very near the retaining wall using gabions.

(3) Both in Case 1 and Case 2, if static analytical power increases, the range where tensile stress and shear stress of background increase is widened.

(4) From the result of dynamic analysis, in Case 1, at the stage of small shaking level, it comparatively well coincide with result of test. On the other hand, if shaking level is increased, analysis cannot express adequately displacement of retaining wall using gabions by test. As well, in Case 2, at the stage of low shaking level, cumulative displacement generated on the retaining wall using gabions cannot be expressed. This comes from the fact that influence of local ruin of back ground generated by collision of retaining wall using gabions back ground and increase of local stress cannot be well expressed.

(5) From the tests and the results of dynamic analysis and static analysis, there is a possibility that in Case 2 of lean type, local cracks are easily generated on the back ground near the retaining wall using gabions and it is supposed that a little bit of swelling is generated in gabions, but problem of stability such as leaning forward is difficult to be generated compared with Case 1, and therefore Case 2 shows the shape with better earthquake resistance.

\section{Acknowledgements}

This study was executed with grant of subsidy for scientific research fund (Grant-in-Aid for Scientific Research B(general) 16H04413 and Grant-in-Aid for Scientific Research B (overseas academic research)16H05746). We would like to express our deepest gratitude to the people concerned. 


\section{References}

[1] Association of Nationwide Disaster Prevention and Japan River Association, Knowledge of gabion (in Japanese), p.166, 1963.

[2] Nakazawa, H., Manandhara, S., Hara, T., Suetsugu, D., Kuribayashi, K., Nishi, T., Sakuraba, T.,Kariya, T.,Ko-chi, Y. and Hazarika, H., Report on damages caused by the 2015 Nepal Gorkha Earthquake, JAEE International Symposium on Earthquake Engineering, pp.2-36, 2015.

[3] Yamada, M., Hayashida, T., Mori., J, Mooney., W, Building damage survey and microtremor measurements for the source region of the 2015 Gokha, Nepal Earthquake, Annuals of Disas. Prev. Res. Inst, Kyoto Univ., No.59 A,2016, pp.65-73, 2016.

[4] Hara, T., Nakazawa, H., Suetsugu, D., Kuribayashi, K., Nishi,T., Tadokoro, Y., Miyoshi, K., Zhang, H., Field survey on damages of gabion structures caused by the 2015 Nepal Gorkha earthquake and examination of specific measures for earthquake resilience improvement, Journal of the Japan Society of Civil Engineers A1, Vol.74, No.4, pp.I_586-pp.I_597, 2018.

[5] Suetsugu, D., Hara, T., Nakazawa, H., Kuribayashi, K., Shinagawa, D., Nishi, T. and Zhang, H., Damage survey on 1gabion structures in the 2015 Nepal Gorkha Earthquake - Physical properties of stone materials packed in the gabion -, 51st Japan National Conference on Geotechnical Engineering(in Japanese), pp.1661-1662, 2016.

[6] Kuribayashi, K., Nishi, T., Zhang, H., Bhattarai, P. K., Hara, T., Suetsugu, D. and Nakazawa, H., Damage survey on gabion structures in the 2015 Nepal Gorkha Earthquake - Construction method to filling materials in gabions -, 51st Japan National Conference on Geotechnical Engineering(in Japanes), pp.1663-1664, 2016.

[7] Nakazawa, H., Hara, T., Suetsugu, D., Kuribayashi, K., Nishi, T. and Hazarika, H., Residual deformation in full-scale shake table test of a gabion retaining wall for road, The 15th International Symposium on Geo-disaster Reduction (15th IS-GdR), p.109, 2017.

[8] Nakazawa, H., Hara, T., Suetsugu, D., Nishi, T., Kuribayashi, K., Miyoshi, K. and Shimomura, S. , Experimental evaluation on earthquake-resistance of road retaining wall using gabion, Journal of Disaster Research, Vol.13, No.5, 2018.
[9] Nakazawa, Hara, T., H., Suetsugu, D., Nishi, T., Miyoshi, K., Shimomura, S., Usukura, K., Kuribayashi, K., Kimura, S., Shibahara, R. : Full scale experiments and stability evaluation on earthquake resistance of gabion retaining wall -part1 overview of residual deformation-, Japan Society of Civil Engineers 73th Annual Scientific Conference(in Japanese), pp.689-690, 2018.

[10] Usukura, K., Nakazawa, H., Nishi, T., Hara, T., Suetsugu, D., Miyoshi, K., Shimomura, S., Kuribayashi, K., Kimura, S., Shibahara, R., Full scale experiments and stability evaluation on earthquake resistance of gabion retaining wall -part2 Stability evaluation-, Japan Society of Civil Engineers 73th Annual Scientific Conference(in Japanese), pp.691-692, 2018.

[11] Nishi, T., Nakazawa, H., Usukura, K., Hara, T., Suetsugu, D., Miyoshi, K., Shimomura, S., Kuribayashi, K., Kimura, S., Shibahara, R, Full scale experiments and stability evaluation on earthquake resistance of gabion retaining wall -part3 Evaluation by FEM analysis-, Japan Society of Civil Engineers 73th Annual Scientific Conference(in Japanese), pp.693-694, 2018.

[12] Hara, T., Suetsugu, D., Manandhar, S., Nakazawa, H., Kuribayashi, K., Nishi, T., Sakuraba, T., Kariya, T., Kochi, Y. and Hazarika, H.: Damage survey on gabion structures in the 2015 Nepal Gorkha Earthquake - Outline of survey -, 51st Japan National Conference on Geotechnical Engineering(in Japanese), pp.1657-1658, 2016.

[13] Duncan, J. M. and Chang, C. , Nonlinear analysis of stress and strain in soils, Journal of the Soil Mechanics and Foundations Division, ASCE,Vol.96, No.SM5, pp.1629-1653, 1975.

[14] Hara, T., Tadokoro, Y., Shibahara, R., Suetsugu, D., Nakazawa, H., Nishi, T., Kuribayashi, K., Evaluation on earthquake resistance of retaining wall using gabions by laboratory tests -Part.1 Shear strengths characteristic of infilling materials-53st Japan National Conference on Geotechnical Engineering(in Japanese), pp.1795-1796, 2018.

[15] Tanaka, Y., Kudo, K., Nishi, K., Okamoto, T., Kataoka, T. and Ueshima,T., Small strain characteristics of soil in Hualien, Taiwan, Soils and foundations, Vol.40, No.3, pp.111-125, June 2000. 